\title{
APLICAÇÃO DO TRIGLICERÍDEOS DE CADEIA MÉDIA (TCM) NA PREVENÇÃO DE ÚLCERAS DE DECÚBITO
}

\author{
Vânia Declair*
}

\begin{abstract}
RESUMO: Aproximadamente 75.000 das 1.000 .000 pessoas hospitalizadas a cada ano desenvolvem Úlceras de Decúbito. Graças à tecnologia avançada, hoje temos várias opções de tratamento destas úlceras, ainda que isto seja dispendioso para os pacientes e hospitais. Porém, melhor que desenvolver um processo curativo, é poder desenvolver um processo preventivo eficaz. Com o objetivo de avaliar a eficácia do uso tópico de triglicerídeos de cadeia média (TCM) na prevenção de Úlceras de Decúbito, a autora utilizou o método duplo-cego em 86 pacientes, onde $50 \%$ foi submetido ao uso de solução com TCM e $50 \%$ ao uso Solução Glicerinada. Em ambos os casos, houve diminuição da instalação de Úlceras de Decúbito, porém, dos pacientes que se submeteram ao uso de solução com TCM, apenas de 2 (dois) desenvolveram Úlcera de Decúbito (Grau 1); e dos pacientes que se submeteram ao uso de Solução com Glicerina, 12 (doze) desenvolveram Úlcera de Decúbito (Graus 1 e 2). Concluiu-se que o TCM é de grande auxílio na prevenção de Úlceras de Decúbito, tem excelente absorção para uso tópico, forma uma película protetora à pele, previne escoriações devido à sua alta capacidade de hidratação e proporciona nutrição celular local.
\end{abstract}

ABSTRACT: Aproximately 75.000 of the 1.000 .000 people hospitalized each year develop pressure sores. It is a big problem - one of the most frustrating and persistent we encounter in daily practice. The purpose of this paper is to evaluate the efficiency of MCT in patients with 1st risc in developing pressure sores. The method consisted of using the double-blind method on the ECU, where 86 patients were randomized trial analyzed; the average hospitalization $=17$ days, with differents pathologies. The average age was 58 years, 1st risc in developing pressupre sores, with the same nursing interventions. Patients with pressure sores at intemation were not analysed. Results: Reductions of developing pressure sores were observed in both groups. Additional reduction was observed in a group that used MCT, where 2 cases of pressure sores apperead (stage I). In another group, we had 12 cases of pressure sores (stage I e II). The conclusion drawn from thesee analysis is that MCT helps to prevent scratches and keeps the skin hydrated. It also helps the nutricional necessity of the skin and is very helpful in preventing pressure sores.

\section{UNITERMOS: Úlcera de Decúbito - Triglicerídeos de Cadeia Média - Prevenção}

\section{INTRODUÇÃO}

Aproximadamente 175.000 dos 1.000 .000 pacientes hospitalizados a cada ano, desenvolvem Úlceras de Decúbito (1). Hoje, graças à tecnologia avançada, temos várias opç̃̃es de tratamento destas úlceras, quan- do já estão instaladas, ainda que este tratamento represente um custo consideravelmente alto para pacientes e hospitais ${ }^{(4)}$. Porém, melhorque aplicarum processo curativo, é poder desenvolver um processo preventivo eficaz, proporcionando assim o bem estar ao paciente e uma boa qualidade da assistência de enfermagem.

\footnotetext{
* Enfermeira da UTI do Hospital Professor Edmundo Vasconcelos. Pós-graduada no Hadassah Medical Center - Jerusalém - Israel.
} 


\section{Revisão Bibliográfica}

Úlcera ou Escara de Decúbito é toda e qualquer lesão, superficial ou profunda, causada pela permanência no leito de pacientes enfermos.

Para que sejam tomadas medidas profiláticas', é necessário que se considere a existência de fatores que influem na instalação e desenvolvimento destas úlceras (1, 2, 5 e 6$)$, os quais são:

Pressão: Exercida por uma força perpendicular à pele, resultante da ação da gravidade, ocasiona a oclusão do fluxo sanguíneo do paciente que fica em uma mesma posição no leito. A pressão maior que $25 \mathrm{mmHg}$ oclui o fluxo sanguíneo dos capilares dos tecidos moles, causando hipóxia, que se não for avaliada a tempo, evoluirá para eventual necrose.

Fricção: É o esfregar da pele do paciente no leito, deixando-a propícia à lesão.

Escoriação: É a combinação dos ef eitos da pressão e friç̧ão. Há produção de hiperemia que evolui para vesículas que se rompem, iniciando assim a lesão aberta da pele.

As Úlceras de Decúbito apresentam quatro estágios durante seu desenvolvimento ${ }^{(2 \text { e } 3)}$. São eles:

$\mathbf{1}^{\circ}$ Estágio: Epiderme e derme lesadas, porém não destruídas. Pele avermelhada, que não retoma ao normal após remoção da pressão.

$2^{\circ}$ Estágio: Epiderme e derme destruídas, com perigo de lesão subcutânea. Pele hiperemiada com presença de bolhas, que podem ou não estar rompidas.

$3^{\circ}$ Estágio: Subcutâneo destruído, com presença de pequena cavidade local. Geralmente há presença de exsudato e pequenas úlceras locais, com pontos necróticos e com secreção.

$4^{\circ}$ Estágio: Úlcera extensa com penetração muscular e/ou óssea. Geralmente com tecido necrótico e presença de infecção local. Estrutura molecularirregular.

Existem áreas, que por serem áreas de apoio ou terem presença de saliência óssea, são consideradas áreas de alto risco de compressão. Logo, são mais suscetíveis à instalação de Úlceras de Decúbito, e dentre elas temos: Região Sacra, Calcâneo, Glúteo, Interglúteo, Região do Maléolo e Omoplata ${ }^{(3,8)}$.

Podemos classificar os pacientes de acordo com seu grau de risco em desenvolver Úlceras de Decúbito. Esta classificação poderá ser realizada de acordo com o estado mental, continência fisiológica, mobilidade, atividade fisica, nutrição, circulação, temperatura corporal e medicação recebida ${ }^{(1)}$. Logo, os pacientes seriam classificados em:

Grau 4: Paciente alerta, com auto-controle fisiológico, deambula sozinho, bem nutrido, com boa circulação periférica, temperatura corporal entre $36^{\circ} \mathrm{C}$ e $37^{\circ} \mathrm{C}$, não fazendo uso de Corticóides, Analgésicos e Antipiréticos.

Grau 3: Paciente apático, com incontinência urinária, sem uso de sonda vesical de demora, move-se com dificuldade, regular perf usão periférica, temperatura entre $37,2^{\circ} \mathrm{C}$ a $37,7^{\circ} \mathrm{C}$, fazendo uso de uma das medicaçōes citadas.

Grau 2: Paciente confuso, com incontinência fecal, mobilidade limitada, nutrição pobre, com sinais de edema, temperatura entre $37,7^{\circ} \mathrm{C}$ a $38,3^{\circ} \mathrm{C}$, fazendo uso de duas das medicações acima citadas.

Grau 1: Paciente comatoso, com incontinência fecal e urinária, imóvel, com total dependência da enfermagem, caquético, com edema moderado que evolui para severo, temperatura corporal maior que $38^{\circ} \mathrm{C}$, fazendo uso de Analgésicos, Corticóides e Tranqüilizantes.

Além disso, convém lembrar que a idade, mobilidade, higiene, patologias como Diabetes, problemas circulatórios, e principalmente o estado nutricional ( 7 , $8,9,10,12)$, são fatores que levam o paciente a um processo catabólico, e que contribuem para a instalação e processo de cura dificultoso destas úlceras, quando já instaladas.

Pacientes portadores de anemia, desidratação, infecção e má absorção proteica, terão mais dificuldades em obter sucesso no tratamento, assim como, serão mais suscetíveis a desenvolverem Úlceras de Decúbito. As proteínas são nutrientes compostos de Carbono, Hidrogênio, Oxigênio e Nitrogênio. $\mathrm{O}$ balanço do Nitrogênico, portanto, é um importante elemento, tanto na saúde, como na doença. O Nitrogênio retido no organismo é usado para síntese de proteínas, que são diretamente responsáveis pela reparação dos tecidos. $\mathrm{O}$ balanço negativo de nitrogênio ocorre na desnutrição, nas infecções, febre, imobilizações prolongadas, etc, levando o paciente à situação de catabolismo, anorexia e diminuição da proteína responsável pela nutrição da pele.

Pacientes hospitalizados têm maior necessidade de nutrientes para reparação dos tecidos e para compensar as modificações relacionadas com sua doença. A febre, por exemplo, aumenta em $7 \%$ os requerimentos calóricos do paciente para cada grau acima do normal $(11,12,13,14,15,16)$. 


\section{Os Triglicerídeos}

Triglicerídeos são compostos de Carbono, Hidrogênio e Oxigênio. Estruturalmente são Ésteres de um Álcool Triídrico e Ácidos Graxos.

Um Ácido Graxo ou Cadeia de Hidrocarbono é descrito com atenção a 3 características: o comprimento da cadeia, o grau de saturação com o Hidrogênio e a localização da primeira cadeia dupla. As propriedades físicas dos Ácidos Graxos estão relacionados à sua estrutura química. Quanto mais insaturado for o Ácido Graxo, mais líquida ou macia será a gordura à temperatura ambiente. A posição dos Ácidos Graxos na molécula de Glicerol influencia as propriedades de digestibilidade e absorção dos Triglicerídeos.

Os Triglicerídeos de Cadeia Média são formas que não ocorrem naturalmente, sendo absorvidos e metabolizados de maneira diferente dos Triglicerídeos compostos de Ácidos Graxos, cujo comprimento é de 8 a 10 átomos (Glicerol) e foram formulados para servir como fonte de gordura dietética para pessoas com problemas de má absorção de gorduras.

As gorduras, devido à sua alta densidade energética e baixa solubilidade, servem com fonte de energia concentrada, poupam proteínas para síntese tecidual, auxiliam a manter os órgãos e nervos do corpo em posição, protegendo-os contra lesões traumáticas e choques, preservam o calor corpóreo ajudando a manutenção da temperatura, auxiliam no transporte e na absorção de vitaminas liposolúveis (11).

Os Ácidos Graxos Essenciais (AGE) considerados mais importantes para o homem são o Linoleico e o Linolênico. Eles têm papéis importantes no tranisporte e metabolismo de gorduras, assim como na manutenção da função e integridade das membranas celulares $(11,12,13)$

Foi demonstrado por HANSEN, WIESE e COLS(11), que o Ácido Linoleico é essencial para crianças, pois cura e previne eczema. A deficiência de AGE também é causa de uma taxa de baixo crescimento e diminuição de resistência às infecçб̃es(11,12).

A solução de TCM apresenta-se como um óleo vegetal de cor amarelo claro, constituído $96 \%$ de Ácidos Graxos de Cadeia Média, que mostra um rápido processo de absorção, principalmente quando ingerido, pois são rapidamente hidrolizados na luz intestinal.

A ingestão do TCM é indicado para o tratamento de ressecção intestinal maciça, betalipoproteinemia com esteatorréia, ascite quilosa, linfangiectasia intestinal, quilotorax, hiperquilomicronemia, hiperlipidemia tipo 1 e síndrome de alça cega que não responde à antibioticoterapia.

Não é descrito o uso tópico de TCM na literatura, porém em 1989, quando testado em ratos, observouse que o Ácido Linoléico tinha grande importância na reparação tecidual, devido à sua alta capacidade de ativaro tecido de granulação (17), o que vem de acordo com nossas observaçð̃es preliminares, que estão sendo realizadas com o uso do TCM para reparação de lesões abertas.

O presente estudo tem como objetivo observar a eficácia do uso de TCM na prevenção de Úlceras de Decúbito.

\section{METODOLOGIA}

No período de Novembro de 1992 a Dezembro de 1993, na UTI do Hospital Professor Edmundo Vasconcelos (SP), usando protocolo pré-estabelecido, foram registrados 86 pacientes, os quais foram submetidos ao método Duplo Cego, onde $50 \%$ usaram solução A e $50 \%$ usaram solução B. Uma destas soluções foi preparada com TCM e a outra com Glicerina, porém o conteúdo das soluções A e B só foi revelado após o término do trabalho.

Estes pacientes estiveram internados na UTI por um período de 10 a 39 dias, média de 17 dias, com idade entre 26 e 78 anos (média=58 anos), grau de risco I para probabilidade de desenvolver Úlceras de Decúbito. Apresentavam: hidratação da pele - $80 \%$ regular, $15 \%$ boa, $5 \%$ altamente desidratada; patologias variadas com evolução para sépsis em $92 \%$ e balanço de nitrogênio em catabolismo em $92 \%$, calculados através da ingestão proteica. Um plano de cuidados foi padronizado, e constava de : mudança de decúbito a cada 4 horas, decúbito elevado a $30^{\circ}$, uso de colchão Casca de Ovo e massagem de conforto com solução previamente estabelecida (A ou B) 3 vezes ao dia.

Realizamos ainda controle de Hematócrito, Hemoglobina, Albumina, Linfócitos e Ferritina. Estes pacientes apresentavam estado de depleção moderada - grave, pois apresentaram a cifra de Linfócitos oscilando entre $1010-710 \mathrm{~mm}^{3}(16)$.

$\mathrm{O}$ perímetro muscular braquial foi verificado na intemação e reverificado a cada 7 dias, porém este parâmetro foi prejudicado devido à maior parte dos pacientes apresentarem anasarca, decorrente de hipo- 
albuminemia e má distribuição de líquido corpóreo.

Foram excluídos os pacientes que apresentaram lesões de pele na internação.

\section{RESULTADOS}

Observamos que houve diminuição de instalação de Úlceras de Decúbito nos dois grupos, porém o grupo que mais manteve a integridade da pele foi aquele que se submeteu ao uso da solução com TCM, onde apenas 2 (dois) pacientes desenvolveram discreta lesão epidérmica sem comprometimento subcutâneo na região interglútea, que foi rapidamente restaurada (2 dias) após o uso do TCM puro diretamente sobre a lesão. Do outro grupo, o qual foi submetido ao uso da solução glicerinada, 12 (doze) apresentaram lesões com comprometimento subcutâneo, sendo que dois com lesão subcutânea tipo necrose, todos em região interglútea ou coccígena.

\section{CONCLUSÃO}

Concluímos, pelos resultados obtidos, que o TCM é de grande auxílio na prevenção de Úlceras de Decúbito, pois tem excelente absorção para uso tópico, forma uma película protetora à pele, previne escoriações devido sua alta capacidade de hidratação e proporciona nutrição celular local, visto que os pacientes protocolados eram desnutridos e estavam em sua maioria, em estado de catabolismo.

\section{REFERÊNCIAS BIBLIOGRÁFICAS}

1. SHANNON, M. Famous Fallacies about Pressure Sores. Nursing, v.14, n.9, p.34-45, 1984

2. BYRNE, N., FELD, M. Overcoming the Red Menace: Preventing and treating Decubitus Ulcers. Nursing, 9, p.55-57, 1984

3. PETERSEN, N., BITTIMAN, S. The epidemiology of pressure sores. Scan.J. Plastic and Reconstructive Surg. 5, p.62, 1971.

4. ROBINSON, C., et al. Decubitus Ulcers in paraplegics: financial implications. CanadianJ. of Public Health. 69, p.199, may/june 1978.

5. BELL, F. et al. Pressure sores - causes and prevention. Nursing Times. 70, p.740, may 26, 1974.

6. LINDAN, O. Etiology of decubitus ulcers: an experimental Study. Arch. Phys. Med. Rehab. 42, p.774-783, 1961.

7. ARNELL, I. Treating Decubitus Ulcers. Nursing Times v.8, n.13, p.50, june 1983.

8. AHMED, M. Ap. Site for Decubitus Care. American Journal of Nursing 82, p.61, january, 1992.

9. CRISP, M. New treatment for pressure sores. Nursing Times 73, p. 1202 , august 4, 1987.

10. Mc CAULEY, R., PLATELL, J., Mc CULLOCH R., Influence of branched amino acid infusion on wound healing. Aust. N. Z. J. Surg. 60, p.471-473. 1990.
11. HANSEN, A.E., et al. Role of linoleic acid in inf ant nutricion. Pedriatrics, 31, p.171, 1963.

12. BLAKBURN, G.L.Manual for the nutrional/metabolic assesment of the hos pitalized patient. Chicago, oct. II-15, 1976.

13. BRISSON, G.J. Lipids in human nutricion. Engle Wood, N. Jersey: J. K. Burgess, Inc. 1981.

14. GOLFERJE, H., FEKL, W. Diagnóstico de la ma nutrición, 6, p.2,3 1979.

15. RUSSO, F.G. O Apoio Nutricional no Paciente Imunocompetente. Rev. Nutrição Enteral e Esportiva. v.2, p.10-13, 1993.

16. CAMPBELL, M.D., ANNES, F.C. Nutricion and immunocompetence. Intensive Care. p.75-76. 1993.

17. MOCH, D., SCHEWE, T., KÚHN, H., SCHMIDT, D., BUNTROCK, $\mathrm{P}$. The linoleic acid metabolite is a strong proinflammatory mediador in an experimental wound healing model of the rat. Biomed Biochim. v.49, n.4, p.201-207, 1990.

Recebido para publicação em 23.1.94 